\title{
PKM PEMANFAATAN LIMBAH KOTORAN SAPI MENJADI BIOGAS SEBAGAI SUMBER ENERGI ALTERNATIF DI KELURAHAN BULUSAN KECAMATAN KALIPURO KABUPATEN BANYUWANGI
}

\section{PKM UTILIZATION OF COW FERTILIZER INTO BIOGAS AS AN ALTERNATIVE ENERGY SOURCE IN KELURAHAN BULUSAN KECAMATAN KALIPURO, BANYUWANGI DISTRICT}

\author{
Abdul Holik*1, Muhammad Habbib Khirzin**, Ardito Atmaka Aji* \\ ${ }^{*}$ Program Studi Agribisnis, Politeknik Negeri Banyuwangi \\ ${ }^{* * *}$ Program Studi Teknologi Pengolahan Hasil Ternak, Politeknik Negeri Banyuwangi \\ Jl. Raya Jember Km 13 Labanasem Kabat Banyuwangi 6846i \\ $\left.{ }^{1}\right)$ abdulholik@poliwangi.ac.id
}

\begin{abstract}
Abstrak
Kelurahan Bulusan didominasi oleh sektor peternakan. Sebagian besar masyarakat bekerja sebagai kuli bangunan dan setiap warga memiliki peliharaan sapi 2-4 ekor. Selama ini limbah kotoran sapi dari hasil usaha peternakan tidak dimanfaatkan dengan baik dan dibuang begitu saja sehingga mencemari lingkungan. Hal tersebut menjadikan tim PKM ingin melaksanakan pengabdian dengan memanfaatkan limbah kotoran sapi. Tujuan dari PKM ini adalah pemanfaatan limbah kotoran sapi menjadi biogas sebagai sumber energi alternatif. Kegiatan ini dibagi menjadi tiga tahap, yaitu tahap sosialisasi, pembuatan instalasi biogas, dan pendampingan. Kegiatan PKM dapat memberikan dampak yang baik untuk masyarakat Kelurahan Bulusan sehingga pencemaran lingkungan dapat teratasi.
\end{abstract}

Keywords : Bulusan, kotoran sapi, biogas

\section{Abstract}

Kelurahan Bulusan is dominated by the livestock sector. Most of the community work as construction workers and each resident owns 2-4 cattles. So far, cattle waste from livestock farming is not used properly and just thrown away, thus polluting the environment. This situation made the PKM team want to carry out community service by utilizing cattle waste. The purpose of this PKM is to use cow dung waste into biogas as an alternative energy source. This activity is divided into three stages, namely the stage of socialization, construction of a biogas installation, and assistance. PKM activities can have a good impact on the community of Bulusan village so that environmental pollution can be overcome.

Keywords: Bulusan, cow dung, biogas

\section{PENDAHULUAN}

Kelurahan Bulusan Kecamatan Kalipuro Kabupaten Banyuwangi memiliki luas wilayah 7,61 $\mathrm{Km}^{2}$ (7,86\% dari total luasan Kecamatan Kalipuro) dengan ketinggian $\pm 6 \mathrm{~m}$ di atas permukaan laut. Kelurahan Bulusan memiliki 2 Dusun, 7 RW, dan 31 RT dengan jumlah penduduk 8.035 jiwa. Menurut data BPS Banyuwangi (2017) Kelurahan Bulusan didominasi oleh sektor peternakan. Populasi sapi ternak di daerah Bulusan sebanyak \pm 607 ekor. Berdasarkan pantauan dilapangan, usaha peternakan sapi yang dilakukan masih dalam skala keluarga atau sebagai usaha sampingan, karena masyarakat Kelurahan Bulusan biasanya bekerja sebagai kuli bangunan. Apabila tidak ada panggilan kerja kuli, maka masyarakat fokus pada mencari rumput dan menggembalakan ternak. Rata-rata masyarakat memiliki 2-4 ekor sapi tiap kepala keluarga.

Kondisi lahan Kelurahan Bulusan sebagian besar adalah lahan tegal dengan kondisi cukup tandus. Hal ini diperparah ketika musim kemarau. Sehingga menyulitkan masyarakat untuk bercocok tanam dan cenderung lebih banyak tumbuh rumput liar. Disisi lain, tingkat pendidikan masyarakat yang relatif rendah, menjadikan masyarakat tidak pernah mengelola lingkungan dengan baik sehingga menimbulkan polusi. Selama ini limbah kotoran sapi dari hasil usaha peternakan tidak dimanfaatkan dan dibuang begitu saja, 
sehingga lingkungan menjadi tercemar. Polusi udara berupa bau tak sedap seringkali

menghinggapi warga sekitar. Padahal, kotoran ternak merupakan limbah organik yang dapat menyebabkan penyakit gastroenteritis [1]

Salah satu upaya dalam penanggulangan polusi yang diakibatkan oleh limbah kotoran sapi ini adalah dengan memanfaatkannya sebagai bahan baku biogas. Dalam pembuatan biogas, perlu dibangun digester biogas secara terpadu antara kandang sapi dan digester biogas. Dalam keadaan normal sapi dewasa mengeluarkan feses sebanyak 20-40 kg selama 24 jam. Tekstur dan warna dari feses yang dikeluarkan ternak tergantung dari kandungan bahan kering dalam pakan dan air yang dikonsumsi ternak. Produksi biogas (metana) tergantung pada kondisi kotoran sapi, residence time, $\mathrm{pH}$, suhu $\left(25-27^{0} \mathrm{C}\right)$ dan toxicity, dengan komposisi yang sesuai proses ini akan menghasilkan biogas dengan kandungan gas metana sebesar $77 \%$ [2]. Tidak semua gas yang dihasilkan oleh digester adalah gas metan, melainkan gas $\mathrm{CO} 2$. Oleh karena itu, gas yang pertama dihasilkan pada hari ke-1 sampai ke-8 harus dibuang karena yang terbentuk adalah gas $\mathrm{CO} 2$. Sedangkan pada hari ke10 sampai hari ke-14 baru terbentuk gas metan (CH4) dan $\mathrm{CO}_{2}$ mulai menurun. Pada komposisi $\mathrm{CH} 454 \%$ dan $\mathrm{CO}_{2} 27 \%$ maka biogas akan menyala [3].

\section{TARGET DAN LUARAN}

Sasaran program pengabdian masyarakat adalah peternak sapi yang ada di Kelurahan Bulusan Kecamatan Kalipuro Kabupaten Banyuwangi. Luaran dari kegiatan ini adalah dibangunnya digester biogas dan pemanfaatan hasil fermentasi biogas dapat diaplikasikan ke dalam kompor.

\section{METODE PELAKSANAAN}

Kegiatan ini dibagi menjadi tiga tahap, yaitu tahap sosialisasi, pembuatan instalasi biogas, dan pendampingan (Gambar 1). Tahap sosialisasi mempergunakan metode musyawarah dimana warga peternak sapi diajak memahami pengelolaan limbah peternakan sapi menjadi biogas. Pada tahap ini, dengan simulasi dan demonstrasi, akan ditunjukkan proses fermentasi yang terjadi dan gas metan yang dihasilkan. Diharapkan pada akhir kegiatan masyarakat mengetahui proses alamiah yang terjadi pada limbah peternakan sapi dan memahami pemanfaatan biogas. Selain itu masyarakat bersemangat untuk mewujudkan pembangunan biodigester dan hasil akhir berupa pupuk organik.

Tahap kedua adalah tahap pembuatan instalasi biogas. Pada tahap ini akan dipilih enam sampai sepuluh orang dari warga kelurahan Bulusan yang mempunyai ternak untuk mendapat pelatihan pembuatan digester dari tim pelaksana yang sudah disiapkan. Diharapkan mereka yang sudah mendapat pelatihan dapat melakukan perancangan dan pemasangan pada saat pemasangan digester. Setelah selesai, masyarakat diajak untuk melihat hasil fermentasi yang telah menjadi energi siap pakai, namun yang ditekankan disini adalah biogas yang dihasilkan memiliki resiko yang rendah. Biogas tidak akan meledak seperti halnya gas LPG sehingga relatif aman digunakan.

Tahap ketiga adalah pendampingan. Dalam tahap pendampingan, masyarakat akan didampingi kurang lebih selama dua bulan untuk memonitor hasil dari pemanfaatan biogas dalam kehidupan sehari-hari. Selain itu, masyarakat didampingi dalam hal perawatan dan perbaikan jika ditemukan masalah dalam pemanfaatan biogas yang sudah dibuat.

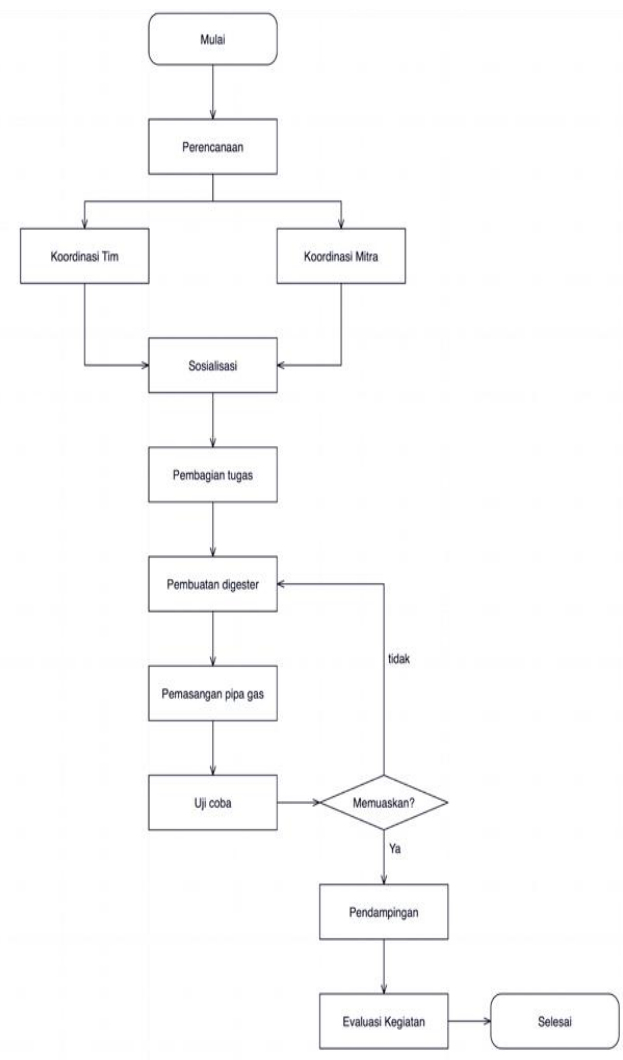

Gambar 1. Tahapan pelaksanaan program kemitraan masyarakat Kelurahan Bulu 


\section{HASIL DAN PEMBAHASAN}

\subsection{Sosialisasi}

Tahap pertama dari kegiatan pengabdian kepada masyarakat ini adalah sosialisasi yang dilaksanakan pada bulan Mei 2019 di teras musholla dekat warga sekitar. Masyarakat umumnya bekerja pada pagi hari sehingga penyuluhan dilaksanakan sore hari. Peserta yang hadir sebanyak 35 orang. Narasumber penyuluhan adalah tim pelaksana PKM.

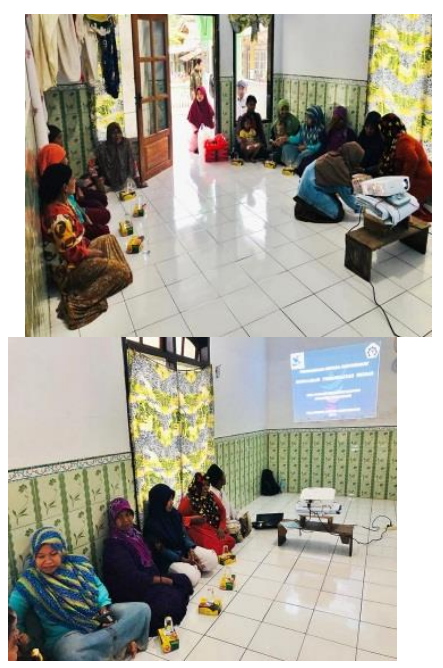

Gambar 1. Sosialisasi pemanfaatan kotoran ternak menjadi biogas

Penyuluhan diikuti oleh bapak-bapak dan ibuibu warga sekitar. Materi sosialisasi yang diberikan adalah:

1. Potensi kotoran ternak sebagai sumber energi alternatif

2. Manfaat dan sumber bahan baku untuk biogas

3. Proses pembuatan digester biogas

4. Uji nyala biogas serta cara pemeliharaan instalasi biogas

Masyarakat sangat antusias ketika mengikuti penyuluhan. Hal ini bisa dilihat dari pertanyaan yang terus muncul selama sesi diskusi, meskipun pada awal materi mereka merasa kawatir. Masyarakat mengira bahwa biogas sama seperti LPG yang bisa meledak dan mudah memicu ledakan. Dengan memberikan pemahaman yang benar masyarakat menjadi mengerti potensi biogas dari kotoran ternak

\subsection{Pembuatan Instalasi Biogas}

Instalasi biogas yang dibuat adalah sistem portabel yang simpel sesuai untuk lahan yang sempit, dan tidak mermakai sistem dome karena perawatannya terlalu rumit. Proses pembuatan instalasi biogas dibagi menjadi beberapa tahap yaitu penggalian tanah, pengecoran dinding tanah dan pembuatan irigasi dari kandang, pembuatan digester, penyaluran pipa, dan terakhir tahap pengisian. Tahap pertama yaitu penggalian tanah. Tanah digali dengan kedalaman dan diameter masing-masing 2 meter. Proses ini menghabiskan waktu 1 hari. Galian tanah sengaja dibuat di dekat kandang sapi agar mudah dalam mengisi dan mencampurkan kotoran ke dalam digester. Setelah tanah digali, selanjutnya dinding tanah ditutup menggunakan bata merah dan semen. Hal ini bertujuan agar air dari tanah tidak masuk ke dalam lubang digester dan lebih mudah proses pembersihan. Saluran irigasi dibuat dari kandang langsung menuju bak penampung.

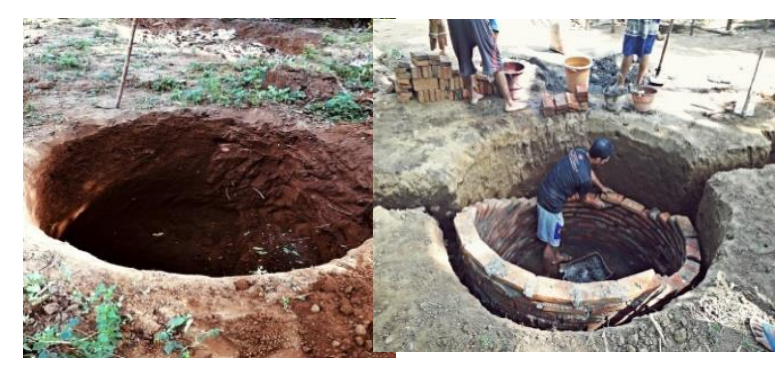

Gambar 2. Penggalian dan pengecoran dinding tanah

Digester yang digunakan adalah model portabel dari tandon air kapasitas 2200 liter. Tandon dibor bagian kiri dan kanan untuk membuat saluran inlet dan outlet. Selanjutnya tandon dimasukan ke dalam lubang galian lalu pipa paralon dimasukan kedalam masing-masing lubang dan di lem. Tutup tandon di bagian atas dikunci dan dilem agar tidak tembus udara (kedap). Setelah pembuatan digester selesai, tahap selanjutnya adalah pemasangan pipa menuju penampung gas . Tutup tandon yang sebelumnya telah diberi lubang disambung dengan pipa lalu dihubungkan dengan selang plastik. Penampung gas terbuat dari plastik bening yang digulung dan diikat disalah satu sisi. Sisi lainnya dihubungkan dengan selang plastik. Selang plastik juga diberi kran untuk dihubungkan ke kompor.
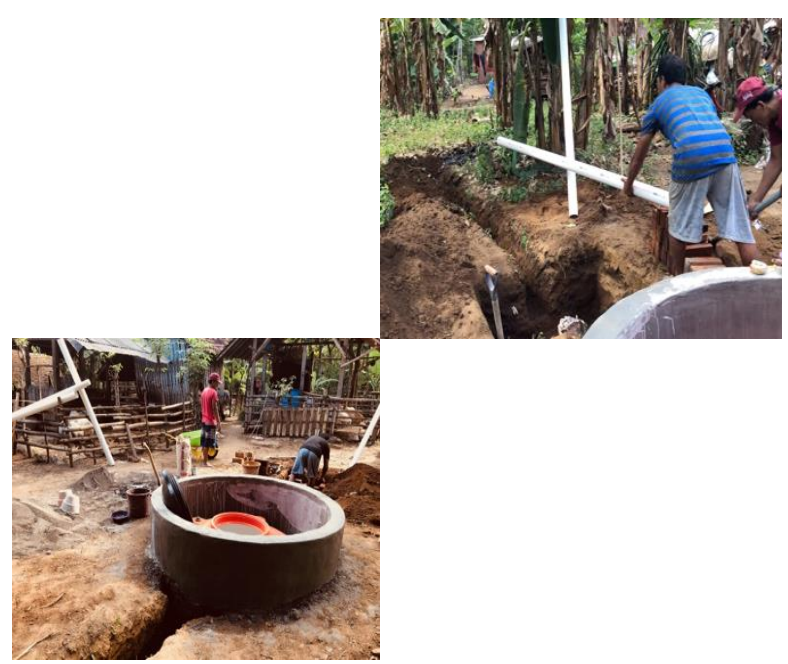

Gambar 3. Pembuatan digester dan penyambungan pipa 
Tahap terakhir dan pembuatan instalasi biogas adalah pengisian. Setelah semua rangkaian instalasi selesai, digester diisi dengan slury (kotoran

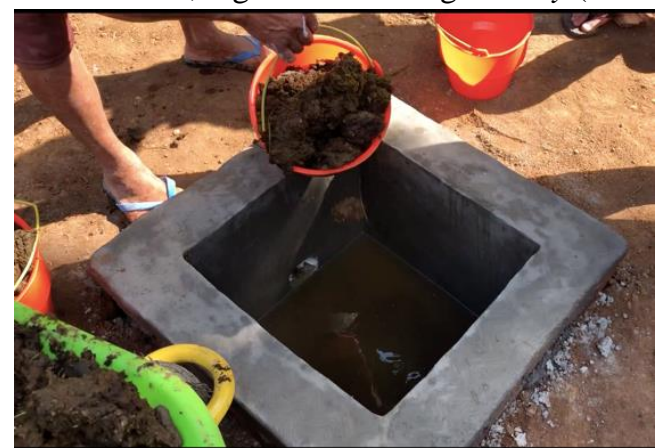

sapi dalam bentuk cair). Perbandingan kotoran sapi dengan air adalah 1:1. Digester diisi slury setengah dari kapasitas maksimum (maksimal digester adalah 2000 liter). Selanjutnya slurry dibiarkan selama 1.5 bulan agar terjadi fermentasi anaerob menghasilkan biogas.

\section{Gambar 4. Pengisian digester}

\subsection{Pendampingan}

Setelah proses fermentasi selama \pm 2 bulan, instalasi dapat berfungsi dengan baik dan menghasilkan gas meskipun nyala api masih kecil. Dengan berhasilnya kegiatan ini, tim pelaksana bangga dapat memberikan hal yang berharga untuk masyarakat Kelurahan Bulusan. Selain menghasilkan biogas, sisa slurry dari digester juga bisa dimanfaatkan menjadi pupuk organik untuk tanaman di sekitar warga.

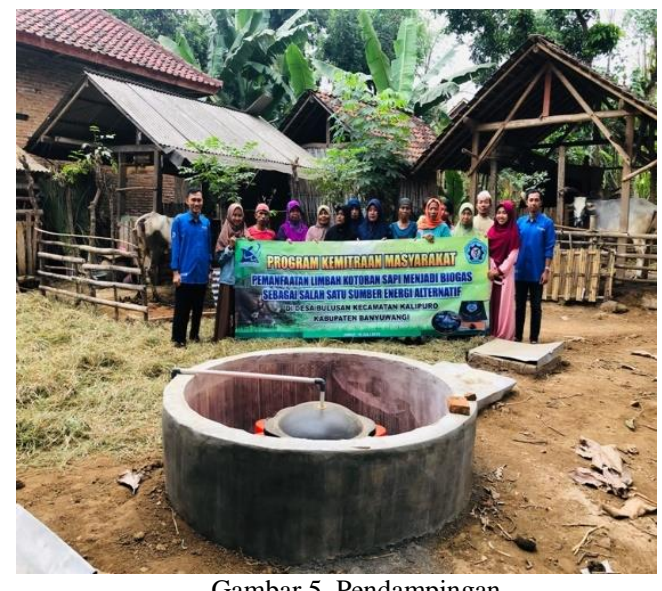

Gambar 5. Pendampingan

\section{KESIMPULAN}

Program pengabdian kepada masyarakat dapat dilaksanakan dengan baik meskipun terjadi perubahan jadual dari rencana semula. Kegiatan ini mendapatkan sambutan baik dari masyarakat yang terbukti dari banyaknya peserta penyuluhan yang datang dan aktif dalam kegiatan diskusi. Kegiatan pengabdian ini mampu memberikan dampak baik bagi masyarakat Kelurahan Bulusan dalam memanfaatkan limbah kotoran sapi menjadi biogas.

\section{UCAPAN TERIMA KASIH}

Ucapan terima kasih disampaikan kepada Pihak direktorat riset dan pengabdian masyarakat (DRPM) Kementerian Riset Teknologi dan Pendidikan Tinggi (RISTEKDIKTI) yang telah memberikan dana pengabdian kepada masyarakat melalui skema program kemitraan masyarakat.

\section{DAFTAR PUSTaka}

[1] Muhammad, F., Hidayat, J.W., Wiryani, E. (2017). Pembuatan Biogas Sebagai Energi Alternatif Dari Limbah Organik Berbasis Peternakan Terpadu dan Berkelanjutan di Ungaran, Kab. Semarang. Jurnal Abdi Insani Unram. volume 4 nomor $139-43$

[2] Utama, C. S., Sulistiyanto, B. (2017) Ipteks Bagi Masyarakat Kelompok Tani Ternak Sapi. Jurnal info. Volume 19, nomor 1 p. $46-54$

[3] Irfan, M., Sukorini, H., Erni, W. D., Zali, M., Heryadi, A.Y.. (2018). Ipteks bagi Wilayah (IbW) Kec. Camplong Sampang Madura : Demplot Biogas dan Produk Pupuk Organik Sebagai Model Desa Mandiri Energi. Jurnal Dedikasi p.107-113. 